\title{
Identification of suitable sites for managed aquifer recharge under semi-arid conditions employing a combination of numerical and analytical techniques
}

\author{
Jafar Alkhatib ${ }^{1,2} \cdot$ Irina Engelhardt ${ }^{3} \cdot$ Martin Sauter $^{2}$
}

Received: 29 September 2020 / Accepted: 30 July 2021 / Published online: 14 August 2021

(c) The Author(s) 2021

\begin{abstract}
Overpumping or overexploitation of groundwater is one of the major threats for aquifer systems in arid and semi-arid areas. Managed aquifer recharge (MAR) has been suggested by many researchers as a sustainable and effective method to alleviate negative impacts of overpumping. Optimizing artificial recharge considers the selection of suitable MAR sites in terms of surface and subsurface characteristics. While surface characteristics at potential MAR sites could be modified (e.g. slope, soil texture, etc.), subsurface characteristics cannot be changed through engineering work. Characteristics of the aquifer, such as depth to groundwater, play an important role in determining the capability of an aquifer to store a specific volume of infiltrated water. Currently, only a limited number of quoted researches are available that consider factors related to aquifer characteristics and the range of these factors to identify optimal MAR sites. In this study, a new approach is presented, that employs numerical groundwater modeling to generate MAR suitability maps considering sub-surface characteristics, such as depth-to-groundwater, aquifer transmissivity and specific yield. Multiple model-runs are conducted to simulate groundwater table response with respect to the volume of infiltrated water. Simulation results are used to calibrate a groundwater mound empirical equation that calculates the groundwater level increase as a function of the transmissivity and infiltrated water volume for a given value of aquifer' specific yield, range of vertical hydraulic conductivities and a specific design and operation conditions of the MAR system. The empirical equation is employed in GIS to spatially calculate the height of groundwater mound beneath a hypothetical MAR site and to generate, based on that, suitability maps for MAR implementation. Assuming that MAR structures capture the median of monthly surface runoff rates at the respective wadi (catchment area), suitability maps are generated for different configurations/scenarios of aquifer hydraulic conductivity in a parameter study. The results highlight the importance of integrating aquifer characteristics (geometry and hydraulic parameters) and expected magnitudes and fluxes of infiltration water in delineating suitable sites for MAR.
\end{abstract}

Keywords Numerical groundwater modeling $\cdot$ Managed aquifer recharge (MAR) $\cdot$ Azraq basin

\section{Introduction}

Due to limited surface water resources in arid and semi-arid areas, groundwater constitutes the main fresh water resource. As a result of an increasing water demand in many regions of the world, aquifers are subject to a heavy overexploitation

Jafar Alkhatib

jaafar_kh@hotmail.com

1 Fugro Germany Land, Wolfener Str. 36 U, 12681 Berlin, Germany

2 Department of Applied Geology, Georg-August-Universität Göttingen, Goldschmidtstr. 3, 37077 Göttingen, Germany

3 Hydrogeology Department, TU-Berlin, Ernst-Reuter Platz 1, Berlin, Germany with a misbalance between abstraction and natural replenishment. Arid and semi-arid regions are characterized by highly variable and erratic precipitation resulting in low groundwater recharge rates and high rates of surface runoff, with excess water being lost if appropriate water storage systems are absent.

Managed aquifer recharge (MAR) is an effective and well-known technology for sustainable management of 
groundwater resources in arid and semi-arid areas (Bouwer 2002). The idea behind implementing MAR is to store excess surface water in the subsurface, which is then abstracted months or years later when it is needed. Based on Bouwer (2002), there are different techniques of MAR, e.g. infiltration basin/dams (surface infiltration), and aquifer storage and recovery (ASR) wells. In this study, the term MAR refers to artificial recharge through surface infiltration techniques.

MAR implementation has been reported in many studies. The main goal of these studies was to determine areas most suitable for artificial recharge. The application of Geographical Information System (GIS) to select suitable sites for MAR has been practiced by many researchers considering surface and subsurface characteristics, such as Ghayoumian et al. (2007); Rahman et al. (2012, 2013). Among studies, considerable variability regarding the number and type of factors to be considered can be observed, with frequently limited integration of subsurface factors, such as aquifer saturated thickness, hydraulic conductivity $(K)$, and storage coefficients or specific yield (Sy).

Alraggad and Jasem (2010) and Mahmoud et al. (2014) assigned suitability classes to MAR implementation based on surface characteristics and aquifer confinement with no integration of hydrogeological factors. Besides surface characteristics and other hydrological factors, Zaidi et al. (2015) and Ghayoumian et al. (2007) integrated the depth to groundwater as a prime factor for locating MAR. Steinel (2012) and Rahman $(2012,2013)$ included aquifer thickness and depth to groundwater. Taheri and Zare (2011) included the storage coefficients (specific yield) and thickness of alluvial layer. Ghayoumian et al. (2005) included aquifer thickness and transmissivity, while Bhuiyan (2015) considered aquifer thickness, transmissivity and storage coefficients (specific yield) in the assessment of MAR suitability.

In most of the published work to date, the analysis of factors starts by assigning unsuitable values for each factor to create a constraint map. Subsequently, suitable values of each factor are classified or standardized according to their degree of suitability and weight. Criteria to assign suitable and unsuitable values to a factor differs between the different studies and a standardized method are still missing, e.g. suitable range for the factor 'depth-to-groundwater' is between 20 and $140 \mathrm{~m}$ (Zaidi et al. 2015), 20-200 m (Steinel 2012) or greater than $10 \mathrm{~m}$ (Ghayoumian et al. 2005; Rahman et al. 2012, 2013).

Definition of unsuitable values of "depth of groundwater table" is of high relevance to avoid the interference of groundwater mounding with the infiltration process, and to ensure feasible pumping costs if injection wells are used. However, a deep groundwater table will reduce the effectiveness of a site for MAR as reduced travel times through the vadose zone are generally considered favorable (Bouwer
2002). A fixed criterion of choosing optimal ranges of depth to groundwater table cannot be provided because the decision should be based on further factors (aquifer transmissivity, specific yield, volume and rate of infiltrated water, etc.) more relevant to evaluate the response of the groundwater table below the infiltration site. For example, should only a low height of groundwater mound be expected a depth to the groundwater table of $140 \mathrm{~m}$ and $200 \mathrm{~m}$, suggested as optimal by Zaidi et al. (2015), Steinel (2012), is not feasible for MAR implementation. On the other hand, a depth to the groundwater table of $10 \mathrm{~m}$, suggested as optimal by Rahman (2012, 2013), will not be suitable for MAR for expected groundwater mounds of large heights.

Therefore, an approach that analyzes relevant factors only qualitatively and does not take into account the volume of the infiltrated water will not be able to ascertain an optimized selection of MAR sites. The response of the groundwater table below the infiltration basin can be a valuable indicator of the suitability of a specific site for MAR. A groundwater mound height displays (i) the integrated total response of the aquifer including its hydraulic properties to artificial recharge and (ii) the total volume of surface water that can be stored. A site is considered as suitable when the groundwater mound resulting from the artificial recharge doesn't reach the ground surface after a specific time period. In literature such quantitative information on the assessment of suitable sites for MAR is limited. Smith and Pollock (2012) applied the analytical solution of Golver (1961) on a spatial scale across the Perth Coastal Plain in Australia, to compute groundwater mounding height with respect to the infiltrated recharge volume, and employed model results to generate suitability maps for MAR implementation.

The application of analytical solutions, e.g. Glover (1961), Hantush (1967), for the calculation of groundwater mounding below an infiltration basin is associated with some simplifications, e.g. uniform saturated thickness, initially horizontal water table, aquifer anisotropy being negligible, etc. On the other hand, the spatial simulation of groundwater mound based on numerical models can be computationally elaborate.

In this study, a new approach is presented, that applies numerical methods for the calculation of the spatial configuration of a groundwater mound with a minimized number of model-runs. Numerical simulations are conducted at a few locations across the study area to calculate the height of the groundwater mound beneath hypothetical MAR basins. The results will be employed to calibrate a simple empirical equation to determine the height of groundwater mound as a function of aquifer transmissivity and volume of infiltrated water. The calibrated equation can then be transformed into a GIS system to spatially evaluate the response of groundwater table to artificial recharge for the total area. Different scenarios of recharge water volumes are also considered. The 
study is carried out for the Azraq basin, Jordan, where the groundwater table is declining since 1990 and water quality is continuously deteriorating. Results are compiled into suitability maps for MAR implementation.

\section{Materials and methods}

\section{Investigated study site}

The Azraq Basin is a transboundary aquifer shared between Syria and Jordan stretching across an area of $12,414 \mathrm{~km}^{2}$. The major part of the basin consists of basaltic rocks, chert plains, and alluvial deposits. Some agricultural activities take place in the North and West of the basin, and in the center around Azraq town (Fig. 1). Precipitation rates range from $200 \mathrm{~mm} /$ year in the North and decrease South- and Eastwards to less than $50 \mathrm{~mm}$. Recharge with an average long-term rate of $1.7 \mathrm{~mm} / \mathrm{a}$ infiltrates mainly in the North and decreases to less than $1 \mathrm{~mm} / \mathrm{a}$ in the South and East (Al-Kharabsheh 1995). Most of the rainfall drains through non-perennial streams and wadis into the central area where it remains on the mudflat of Qaa'Al Azraq for a month or two until it evaporates. Many wadis, e.g. Rajil, Aseikham, Mudeisisat, Unqiya are characterized as wide shallow flow-beds with relatively low slopes (Fig. 3) (MWI and GTZ 2003).

There are three main aquifer systems in the basin: an upper, middle, and deep aquifer systems. The upper aquifer complex is an unconfined aquifer consisting of four members hydraulically connected: quaternary sediments, basalt, Shallala (B5) and Rijam (B4). The Basalt aquifer covers the
Northern area and has a variable hydraulic conductivity of $3 * 10^{-6}$ to $1^{*} 10^{-3} \mathrm{~m} /$ day (Arabtech Consulting Engineering 1994). The outcrop of the B4/B5 aquifer is developed in the center and South of the basin. The B4 aquifer consists of limestone and chalk, while the B5 formation contains marly clayey layers and acts as an aquitard in the North between the basalt and B4 formation. In the South, it consists of sandy layers and acts as an aquifer (Hober et al. 2001). Groundwater flows from the edges of the basin and converges towards the center where it drains via two springs. These springs dried up in 1990 as a result of groundwater overabstraction. The middle aquifer system consists of a limestone aquifer composed of two formations B2/A7 and without an outcrop in the basin. It is developed at a large depths and developed only to a low degree used for groundwater abstraction (Hober et al. 2001). Drastic declines of the groundwater table, salt water intrusion and water quality problems have been documented in many studies in the basin as a result of heavy overpumping (El-Naqa et al. 2007; Goode et al. 2013).

\section{Groundwater model for the study area}

A calibrated groundwater flow model prepared for the Azraq basin (Alkhatib et al. 2019) was employed as the basis in this study to model groundwater mounding beneath a planned infiltration basin. The model domain covers an area of 8672 $\mathrm{km}^{2}$. The code MODFLOW (McDonald and Harbaugh 1988) was used for the simulation and the model domain was discretized into 4000 grid cells. Runoff events between 1970 and 2012, calculated with the Curve Number (CN) method (SCS 1985) were used to calculate the water budget
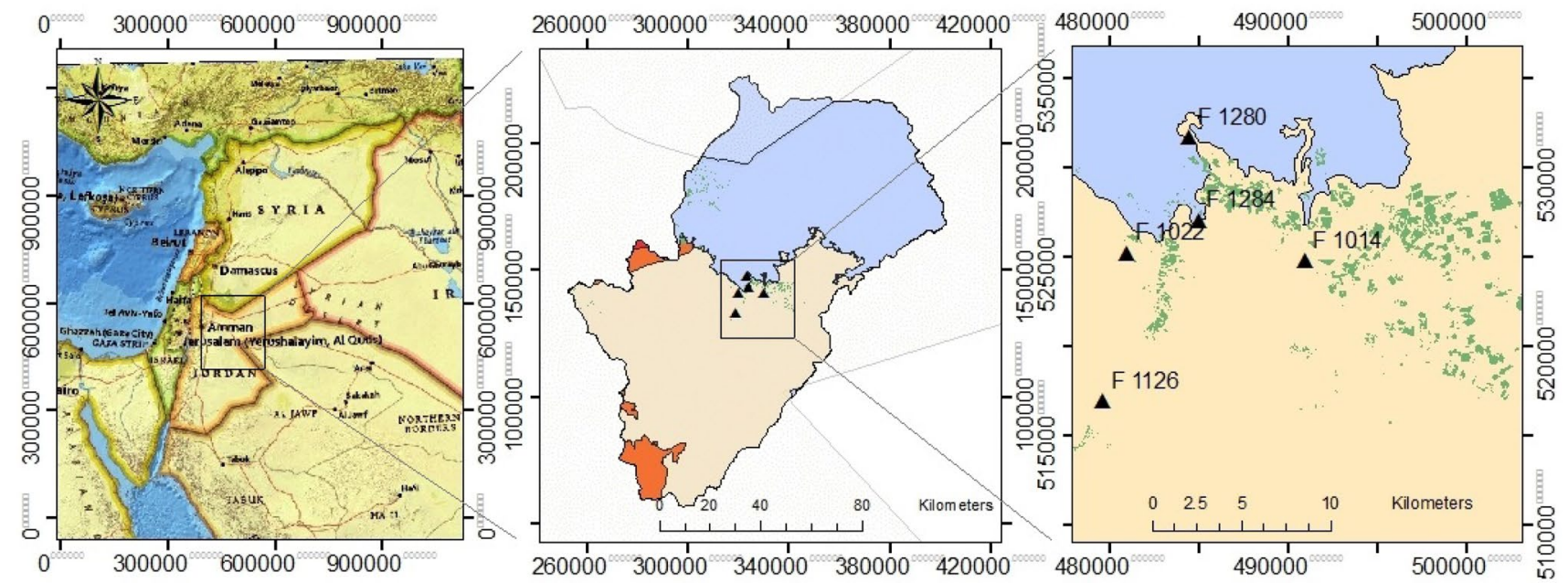

Outcropping aquifers

B4/B5

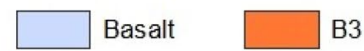
B3

Farms

- Monitoring wells

Fig. 1 Location of the Azraq basin (National Geographic, ESRI) showing farmland, monitoring wells, outcrop of the aquifers based on data from the Ministry of Water and Irrigation, Jordan 
Fig. 2 Work flow to define the scenarios and model design for the two aquifer system (the basalt aquifer and B45)
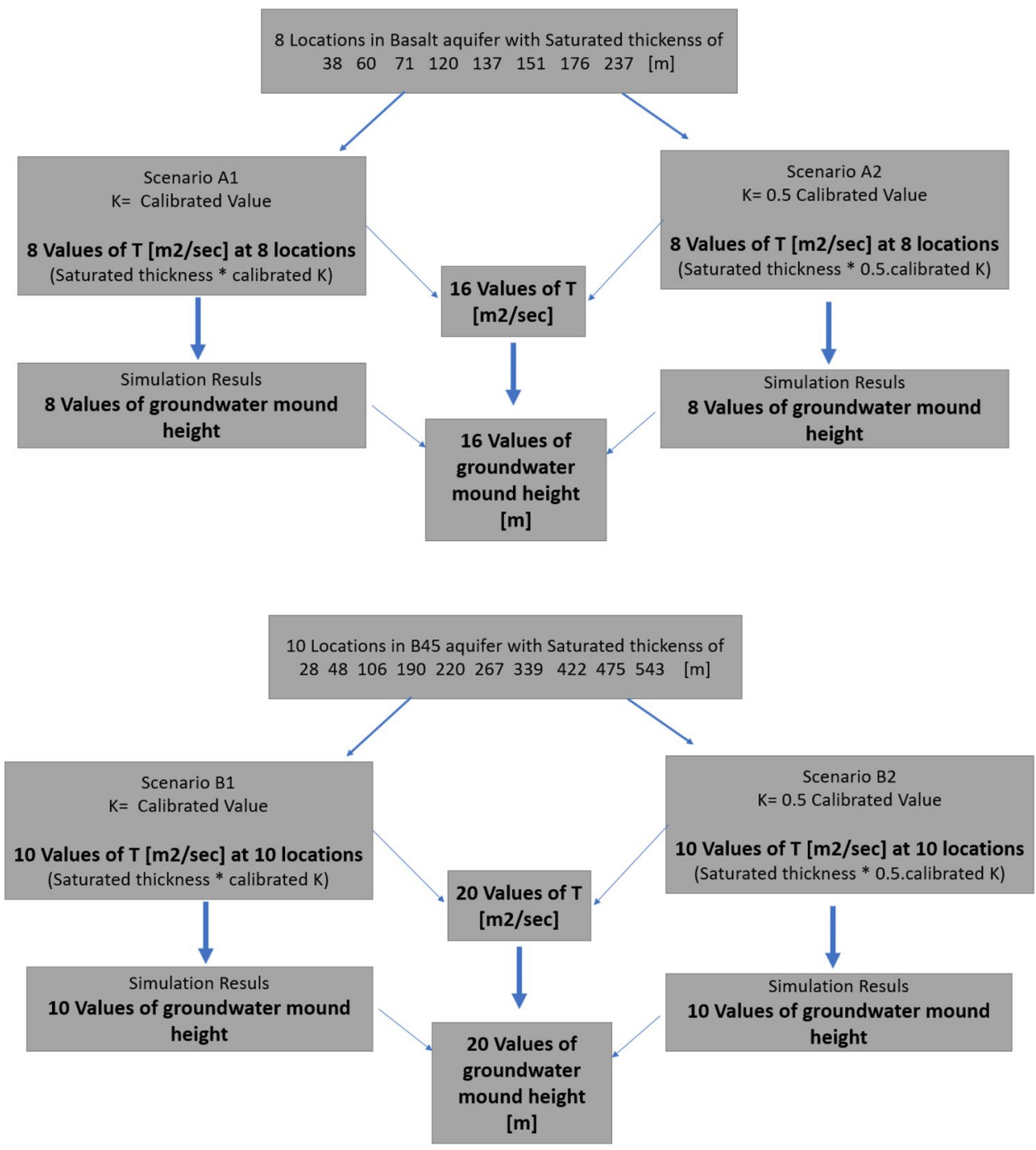

of each Wadi in the model domain and assign accordingly groundwater recharge.

The model was calibrated for steady-state conditions first and later for transient conditions.

For the simulation of MAR operations, the model grid was refined at and around the locations of hypothetical MAR structures $(50 \mathrm{~m} * 50 \mathrm{~m})$ to be able to better simulate the development of groundwater mounds. In vertical direction, the model is discretized into three different layers: the upper aquifer complex (Basalt and B4/5 aquifers), the B3 aquitard, and the middle aquifer complex (B2/A7 aquifer). Each aquifer layer was subdivided into 3 layers resulting in a total number of 9 layers. Calibration of the shallow aquifer system was based on measured piezometric pressure head distribution in the basin before the groundwater abstraction begun as well as on spring discharge and groundwater level fluctuations recorded in the observation wells (Fig. 1).

Calibrated values of horizontal hydraulic conductivity range between $1.7 * 10^{-4}$ and $1.3 * 10^{-5} \mathrm{~m} / \mathrm{sec}$ for the basalt and B4/5 formations, respectively. The specific yield Sy was estimated to range between 0.001 and 0.01 for the Basalt and B4/5 formations, respectively.

Simulations of groundwater mounding were conducted for transient conditions for a period of 15 days using daily time-steps. The piezometric head distribution simulated for the year 2012 provides the initial conditions for the simulation of the MAR.

\section{Assumptions for the simulation of groundwater mounding}

Simulation of a groundwater mound underneath a MAR structure consists of a local model that requires site-specific information on the aquifer characteristics (saturated thickness, horizontal and vertical hydraulic conductivity, specific yield) as well as on size, geometry, and operation technique of the infiltration basin. Application of a local model to 
simulate groundwater response spatially across the aquifer requires some further simplifying assumptions:

\section{MAR basin design}

The impact of MAR on the groundwater table can vary with respect to its design (size and geometry) and operating conditions. MAR structure is simulated as a series of successive infiltration basins, each with a capacity of $0.25 \mathrm{mio} \mathrm{m}^{3}$, and a dimension of $200 \mathrm{~m} \times 200 \mathrm{~m}$. The number of basins is a function of the collected water volume.

\section{Runoff events and discharge water volume}

Preliminary analysis of the characteristics (volume and variability) of the totally available water volume is important to select relevant infiltration scenarios. In semi-arid regions, such as the Azraq basin, runoff resulting from storm events is the main source for artificial recharge. For the initial design of MAR structure, the available water volume is calculated.

Analysis of runoff events between 1970 and 2012, calculated with the Curve Number (CN) method (SCS 1985) shows that the frequency of runoff events range between 1.2 and 1.7 events per month for the different wadis. Therefore, monthly values derived from the median of monthly surface runoff for the different wadies are used for the definition of scenarios for available water volumes (Table 1). Simulations of the groundwater mounding process were conducted for four scenarios of available water volumes $(0.25,0.5,0.75$, 1) mio $\mathrm{m}^{3}$.

\section{Simulation time}

Infiltration rate of water into the aquifer is determined by the total volume of water and the infiltration time. For the same amount of water, the higher the infiltration rate, the higher the resulting groundwater mound. Time required for water to infiltrate into the aquifer can be computed based on the infiltration rate, thr Deviation from ough the top soil layer. Infiltration rates can be estimated roughly based on vertical hydraulic conductivity, however, this method does not provide an accurate estimate of infiltration rate because the real ratio of vertical hydraulic conductivity, $K_{\mathrm{V}}$, to infiltration rate (e.g. Lee et al. 1992; Heisig and Prince 1993) can vary by several orders of magnitude (Smith and Pollock 2012).
Infiltration tests within the wadi Butum resulted in infiltration rates between 0.15 and $0.24 \mathrm{~m} /$ day (Abu-Taleb 1999). Assuming this infiltration rate, a water volume of $0.25 \mathrm{mio} \mathrm{m}^{3}$ that is applied to a single basin $(200 \mathrm{~m} \times 200 \mathrm{~m})$ would require 26-41 days to infiltrate through the soil layer into the aquifer (neglecting evaporation losses). Within desert dams, it is preferred to enhance the infiltration rate using trenches/wells to achieve a shorter residence times within shallow soil layer to minimize evaporation losses. In this study, an enhanced uniform infiltration rate is assumed with a constant infiltration time of 15 days.

\section{Transmissivity and specific yield}

Calibrated values of horizontal hydraulic conductivity for each formation of the shallow aquifer system (Basalt and the B45) are applied in the simulation. However, horizontal hydraulic conductivity estimated at regional scale might be different with respect to hydraulic conductivity at localscale. The scale dependence of $K$ is accounted for by varying $K$ in the simulation, and considering a second scenario of $K$ (50/100 of the calibrated value).

The distribution of saturated thickness of the aquifers can be defined at higher accuracy by subtracting the elevation of groundwater table from the elevation of the aquifer base. Saturated thickness is highly variable ranging between $20 \mathrm{~m}$ and more than $700 \mathrm{~m}$. Simulations were conducted at various locations with varying saturated thicknesses (basalt: 38 , $60,71,120,137,151,176,237 \mathrm{~m}$ and for B4/5 aquifer: 28 , 48, 106, 190, 220, 267, 339, 422, 475, $543 \mathrm{~m}$ ).

A ratio of 10:1 is used for the ratio between horizontal and vertical hydraulic conductivity. Values of specific yield, Sy, were derived from model calibrations (Alkhatib et al. 2019). Additionally, 50/100 of the above calibrated Sy values were applied to analyze the sensitivity of Sy for the model results.

\section{Presentation of simulations results}

Simulations of groundwater mound heights are performed for 8 locations within the Basalt aquifer, and 10 locations within the B4/5 aquifer, for 4 scenarios of available water volumes, as presented under "run-off events and discharge water volumes", and for 3 scenarios for the basalt aquifer (A1, A2, A3), and 3 scenarios for the B4/5 aquifer (B1, B2, B3) (Table 2).

Table 1 Median water volume of monthly surface runoff for selected wadis

\begin{tabular}{|c|c|c|c|c|c|c|c|}
\hline & Rajil & $\mathrm{U}-\mathrm{B}-\mathrm{H}$ & Mudeisisat & Hassan & Ghadaf & Aseikham & Jesha \\
\hline Median water volume of monthly surface runoff $\left(\mathrm{mio}^{3}\right)$ & 2 & 0.35 & 0.87 & 0.5 & 0.75 & 0.2 & 0.3 \\
\hline
\end{tabular}


Table 2 Parameter study and scenario definition

\begin{tabular}{llll}
\hline & Horizontal $K, \mathrm{~m} / \mathrm{sec}$ & Vertical $K, \mathrm{~m} / \mathrm{sec}$ & Sy $[-]$ \\
\hline Scenario A1 & Calibrated value $\left(1.7^{*} 10^{-4}\right)$ & Calibrated value $\left(1.7^{*} 10^{-5}\right)$ & Calibrated value $(0.001)$ \\
Scenario A2 & $0.5^{*}$ calibrated value $\left(8.6^{*} 10^{-5}\right)$ & $0.5^{*}$ calibrated value $\left(8.6^{*} 10^{-6}\right)$ & Calibrated value $(0.001)$ \\
Scenario A3 & Calibrated value $\left(1.7^{*} 10^{-4}\right)$ & Calibrated value $\left(1.7^{*} 10^{-5}\right)$ & $0.5 *$ calibrated value $(0.0005)$ \\
Scenario B1 & Calibrated value $\left(1.3^{*} 10^{-5}\right)$ & Calibrated value $\left(1.3^{*} 10^{-6}\right)$ & Calibrated value $(0.01)$ \\
Scenario B2 & $0.5^{*}$ calibrated value $\left(6.9^{*} 10^{-6}\right)$ & $0.5^{*}$ calibrated value $\left(6.9^{*} 10^{-7}\right)$ & Calibrated value $(0.005)$ \\
Scenario B3 & Calibrated value $\left(1.3^{*} 10^{-5}\right)$ & Calibrated value $\left(1.3^{*} 10^{-6}\right)$ & $0.5 *$ calibrated value $(0.01)$ \\
\hline
\end{tabular}

Calibrated values refer to those of Alkhatib et al. (2019)

The resulting 16 values for transmissivity of the Basalt (resulting from Scenarios A1 and A2), and 20 values of transmissivity for B45 (resulting from Scenarios B1 and B2) are plotted against their corresponding results of simulated groundwater mound height for each scenario of water volume. Figure 2 shows the individual work-steps. The resulting data points can be used to calibrate the empirical equation that computes groundwater mound height for the Basalt aquifer by curve fitting.

\section{Empirical equation for the groundwater mound height}

For an aquifer with a constant value of Sy and $\mathrm{Kv}$, and a fixed design and operation technique, the height of groundwater mound is directly proportional to the volume of infiltrated water $(W)\left[\mathrm{m}^{3}\right]$, and inversely proportional to aquifer transmissivity $(T)\left[\mathrm{m}^{2} \times\right.$ day $\left.^{-1}\right]$.

While analytical solutions are necessarily associated with simplifications (flat groundwater table, uniform saturated thickness in the aquifer, etc.), numerical solutions avoid these simplifying assumptions and can calculate groundwater mounding adapted to the specific conditions. However, in this study, simulation results of groundwater mound height calculated at a few locations within the aquifer are used to calibrate the empirical equation (EE). The EE calculates the groundwater mound height at further locations within the aquifer characterized by variable initial conditions and aquifer geometry, resulting in an error $\varepsilon$ in the computed GWM height. The total height of the groundwater mound is calculated with:

Height of GWM $=f\left(\frac{W}{T}\right)+\varepsilon$.

Different equations (linear, exponential, etc.) are tested empirically to describe the relationship between groundwater mound height, aquifer transmissivity and infiltrated water volume. Coefficients are empirically introduced and calibrated for each aquifer by curve fitting through data points obtained from simulation results for the scenarios.
The regression coefficients are estimated using the Generalized Reduced Gradient algorithm (Abadie and Carperntier 1969).

\section{Generation of suitability maps}

A suitability map for MAR implementation is generated based on subsurface characteristics. The ultimate goal of MAR is to reduce groundwater decline. Therefore, MAR is favorably implemented close to the center of the basin where the majority of wells (domestic and irrigation) are located (Fig. 3).

Derived equations are applied spatially to prepare a raster of groundwater mound height for the median of monthly runoff and two scenarios of hydraulic conductivity (calibrated and 50\% calibrated values) using the raster algebra tool in ArcGIS. A raster of the distribution of saturated thickness of the shallow aquifer system, a raster of the median of monthly runoff in the different wadis, and a raster of calibrated $K$ and $50 \%$ calibrated $K$ of the formations (basalt and B4/5) are the input values for the calculation.

Additionally, a raster of the distribution of the depth to the groundwater table is prepared by subtracting a USGS Digital Elevation Model (DEM) from the simulated distribution of heads for the year 2012. Suitability maps are then generated from subtracting the raster of groundwater mound height from the raster of depth to groundwater. Negative values on this map delineate unsuitable sites for MAR. All maps have a resolution of $30 \times 30 \mathrm{~m}$.

\section{Results and discussion}

\section{Derived empirical equation of groundwater mound height}

The empirical equation that computes groundwater mound height as a function of the volume of infiltration water $(W)$ $\left[\mathrm{m}^{3}\right]$ and aquifer transmissivity was identified as: 
Fig. 3 Wadies in Azraq basin, area of MAR model

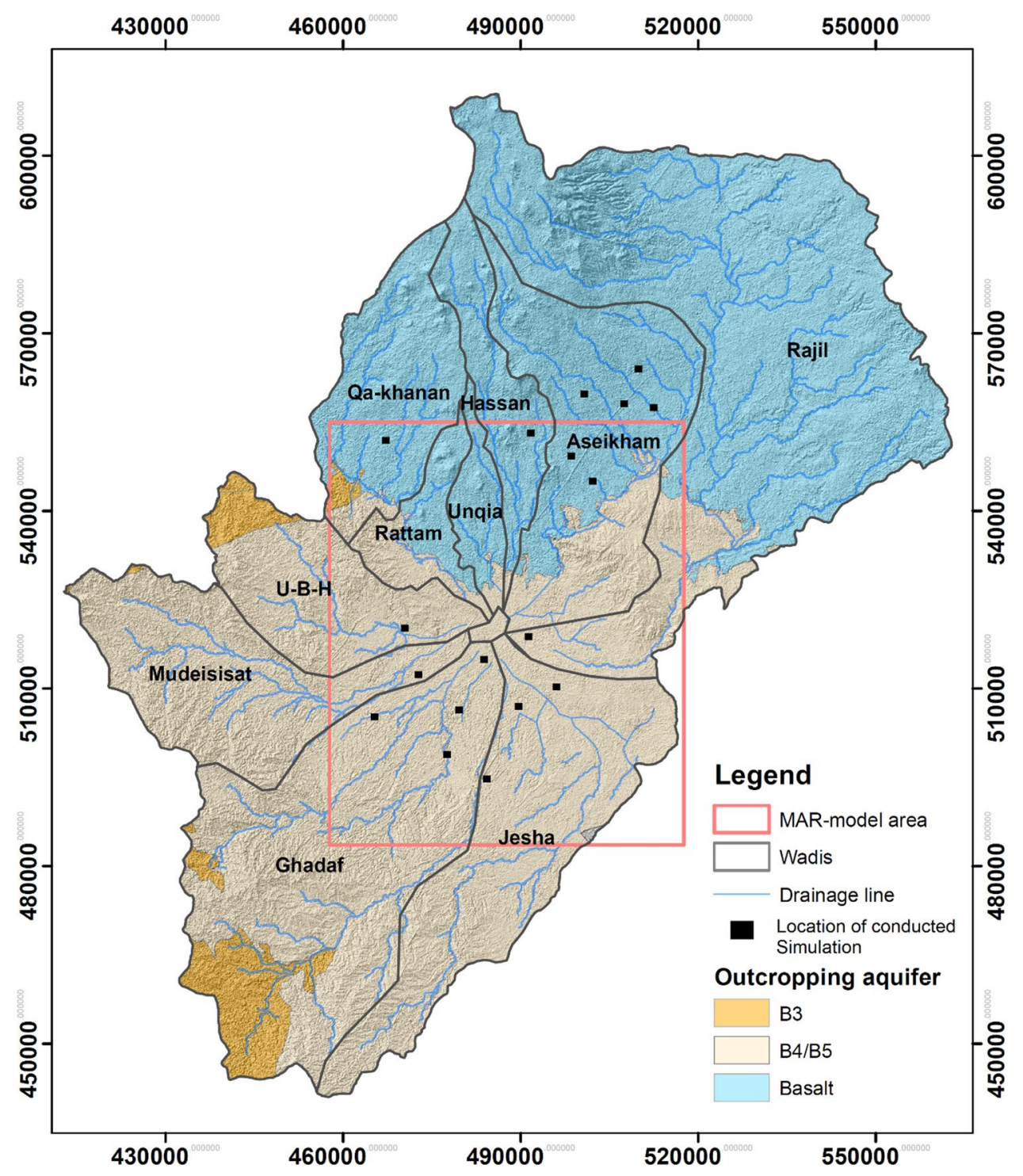

GWM height $=\frac{0.33 * 10^{6}+W}{32} * \frac{1}{357+T}, \quad e(-2,+3)$.

where $\alpha, \beta$ and $\delta$ are regression coefficients calibrated for each individual aquifer formation, e is the residual (difference between calculated and "measured" values), which describes the goodness of fit. The magnitude of $e$ reflects the error $\varepsilon$ from Eq. (1). The coefficients values reflect the variable hydraulic characteristics of the different aquifers $\left(\mathrm{Sy}, K_{\mathrm{v}}\right)$ as well as variable shapes and design of the infiltration basin.

\section{Suitability of the basalt and B45 aquifer for MAR}

The 16 values of simulated groundwater mound height of scenarios (A1 and A2) were used to calibrate Eq. (2) (Fig. 4).
Similar as for the basalt aquifer, Eq. (2) was calibrated using simulation results from scenarios (B1 and B2) (Fig. 5). Equation 4 shows that two sets of coefficients were required to describe the relationship in Eq. 2 for two ranges of transmissivity $(T>60$ and $T<60)$. Ranges of expected errors $(e)$ are displayed next to each equation.

GWM height $=\left\{\begin{array}{lll}\frac{0.5 * 10^{6}+W}{124.2} * \frac{1}{11.6+T}, & T<60, & e(-19,+18) \\ \frac{0.6 * 10^{6}+W}{47.8} * \frac{1}{111.8+T}, & T>60, & e(-9,+9)\end{array}\right.$. 
To validate the equations, additional simulations were conducted for the basalt and B4/5 aquifers. Groundwater mound height was calculated using Eqs. (3) and (4) and the results were compared to simulated groundwater mound height. The results are shown in Table 3 . The results show that the prediction of groundwater mound is sufficiently accurate and the equation could be used for spatial regression of the entire area as well as other locations outside Jordan.

Groundwater mound height was calculated for the total study area employing Eqs. (3) and (4) that allowed the construction of MAR suitability maps (Fig. 6). Suitability maps for MAR in the area show the viability of implementing MAR over a wide area of northern Wadis (Hassan, Aseikham) that coincide with the Basalt aquifer. The suitability of sites for MAR in wadis over the B4/5 aquifer is poor. Figure 6 shows that the area over Jesha Wadi that was considered as suitable have been classified as unsuitable when hydraulic conductivity is reduced by $50 \%$.

After deleting unsuitable sites for MAR, suitability levels (very suitable, suitable, and less suitable) can be derived using uniform criteria over the study area, with the lowest the depth to groundwater is, the higher the suitability (Fig. 7).
Fig. 4 Simulated groundwater mound height $[\mathrm{m}]$ versus $T\left[\mathrm{~m}^{2} /\right.$ day] for the Basalt aquifer and Scenarios 1, 2, 3, and 4

Fig. 5 Simulated GW-mound height [m] against $T\left[\mathrm{~m}^{2} /\right.$ day] values of the B45 aquifer, Water scenarios $(1,2,3,4)$
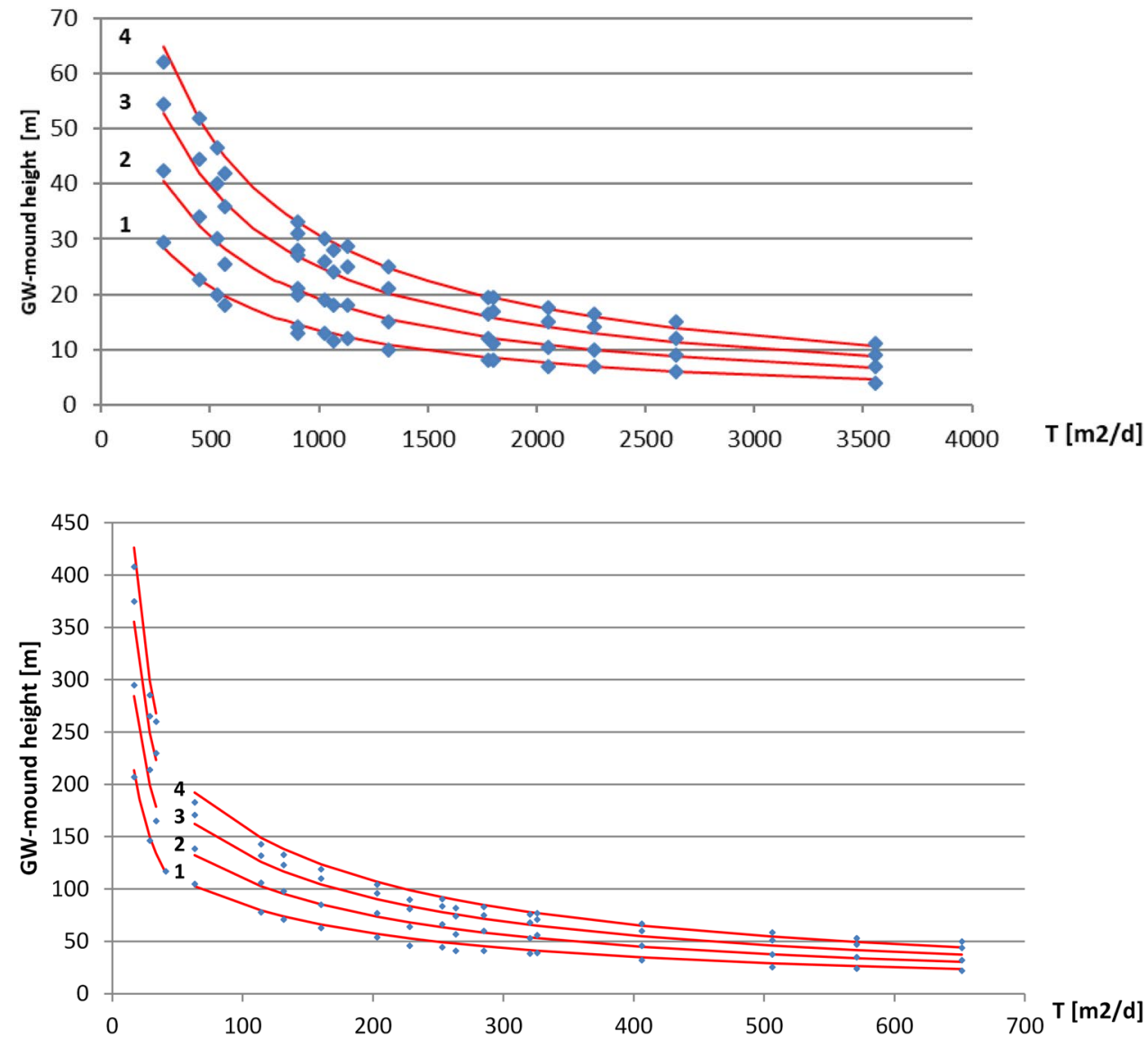

Table 3 Validation of calibrated equation, calculated vs. observed groundwater mound height

\begin{tabular}{llllllc}
\hline Aquifer & $\begin{array}{l}\text { Saturated } \\
\text { thickness }[\mathrm{m}]\end{array}$ & $T\left[\mathrm{~m}^{2} /\right.$ day $]$ & $\begin{array}{l}\text { Infiltrated vol- } \\
\text { ume }\left[\mathrm{mio} \mathrm{m}{ }^{3}\right]\end{array}$ & $\begin{array}{l}\text { Observed } \\
\text { GWM-height } \\
{[\mathrm{m}]}\end{array}$ & $\begin{array}{l}\text { Calculated } \\
\text { GWM-height } \\
{[\mathrm{m}]}\end{array}$ & Error [m] \\
\hline Basalt & 65 & 975 & 0.5 & 19.79 & 19.59 & 0.2 \\
Basalt & 82 & 1230 & 0.5 & 16.15 & 16.44 & -0.29 \\
Basalt & 140 & 2100 & 0.5 & 10.96 & 10.62 & 0.34 \\
B4/5 & 176 & 211.2 & 0.5 & 75.38 & 71.78 & 3.6 \\
B4/5 & 238 & 285.6 & 0.5 & 56.44 & 58.34 & -1.9 \\
B4/5 & 451 & 541.2 & 0.5 & 37.10 & 35.50 & 1.6 \\
\hline
\end{tabular}



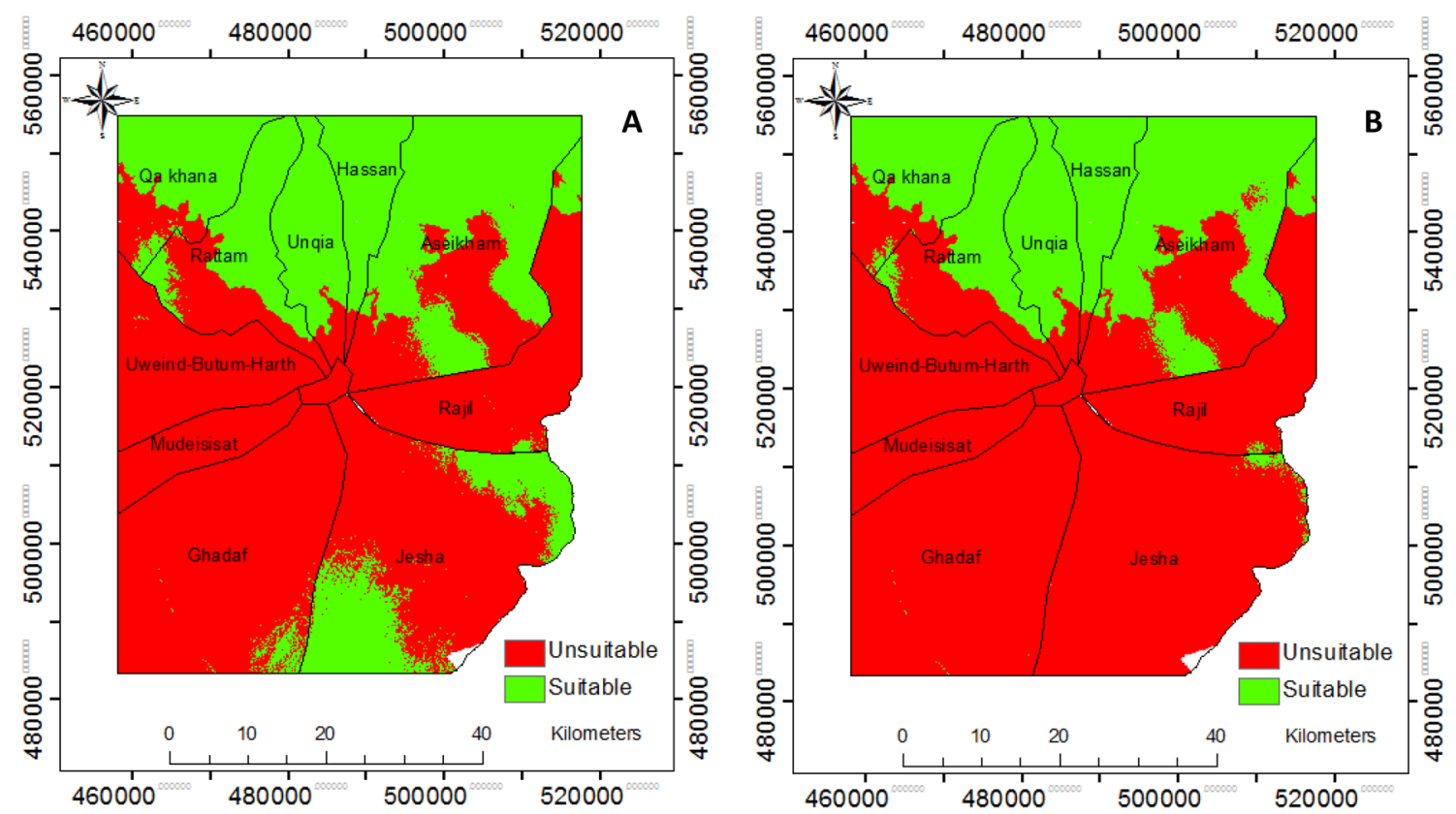

Fig. 6 Suitability maps for MAR. Scenarios (A: calibrated K, 50th of Runoff, B: 50\% calibrated K, 50th percentile of Runoff)

Fig. 7 Suitability maps for MAR implementation with suitability degrees based on subsurface characteristics (calibrated $K$, 50th percentile of Runoff) (3: very suitable, 2 : suitable, 1 : less suitable, 0: not suitable)

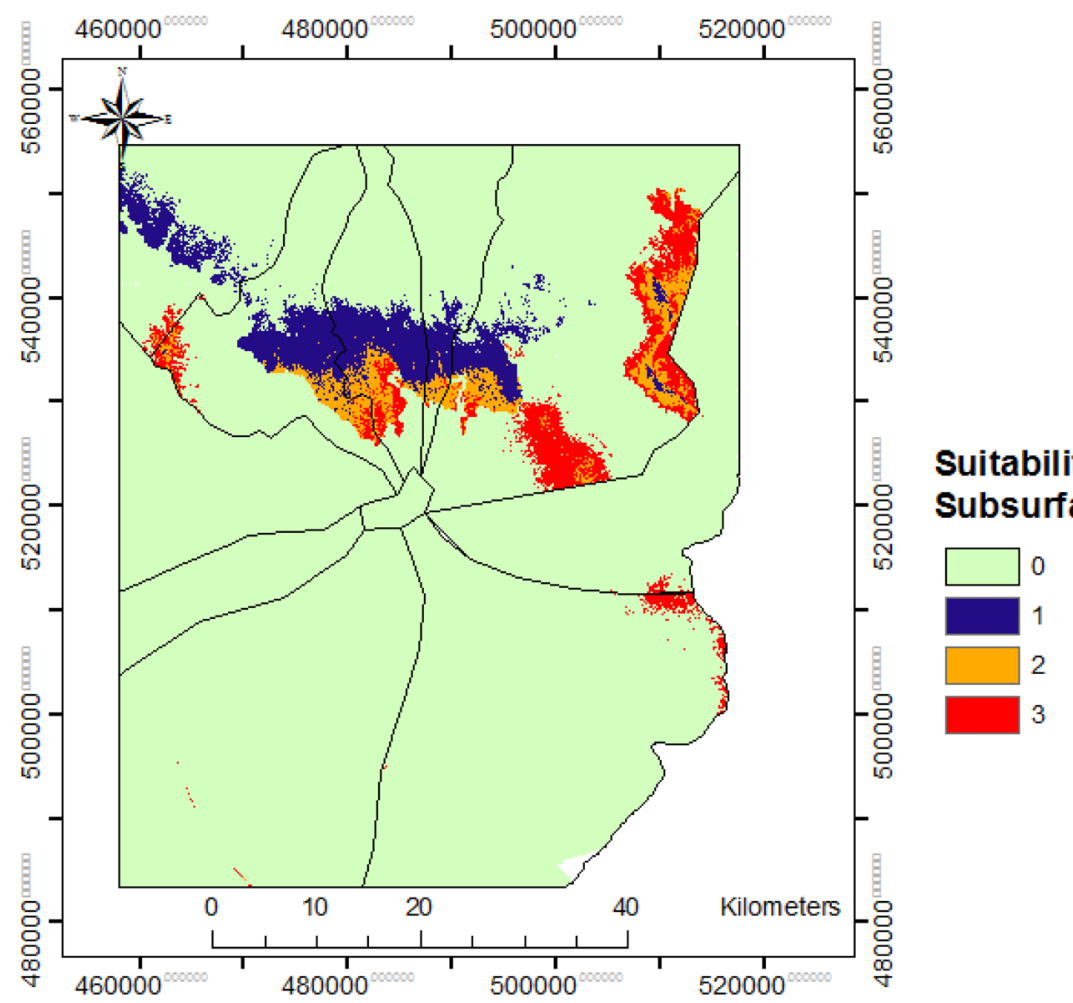

by $50 \%$. This is attributed to the fact that infiltrated water by MAR operations is transmitted away from MAR location a lower flow rate.

Simulation results of scenarios A1 and 3 for the Basalt aquifer show that for a $50 \%$ reduction in the specific yield, fer show that groundwater mound increases between 50 and
$80 \%$ as a result of a reduction in hydraulic conductivity $(k)$

Simulation results of Scenarios A1 and 2 for the Basalt aqui- 
changes in groundwater mound height range between 1 and $6 \%$. Simulation results of Scenarios A1, 2 and 3 for the Basalt aquifer are summarized in Fig. 8.

Similarly, simulation results of scenarios B1, 2 and 3 for the B4/5 aquifer show that groundwater mound height increased between 50 and $80 \%$ as a result of a reduction in horizontal and vertical $K$ by $50 \%$, and between 1 and $8 \%$ as a result of a $50 \%$ reduction in Sy.

Using Eqs. (3), groundwater mound height can be calculated for the basalt aquifer with an error ranging between $-2 \mathrm{~m}$ and $3 \mathrm{~m}$ and a value of Root-mean-square deviation (RMSD) of $1.12 \mathrm{~m}$. This indicates that the results are computed with a lower uncertainty using the derived equation.
The range of error for the B $4 / 5$ aquifer was determined to be higher than those for the basalt aquifer attributed to its low transmissivity. Additionally, for values of transmissivity $\left(T<60 \mathrm{~m}^{2} /\right.$ day) data points could not be fit with the same equation as the rest.

Therefore, another equation was calibrated for $T<60$ $\mathrm{m}^{2} /$ day to describe the relationship between groundwater mound height and transmissivity. Value of RMSD is 4.43 for $T>60 \mathrm{~m}^{2} /$ day and 76.79 for $T<60 \mathrm{~m}^{2} /$ day. This shows that for lower values of the aquifer transmissivity, the results are more sensitive to initial groundwater head, aquifer geometry, vertical $K$, and other parameters related to aquifer heterogeneity. Additionally, this can be attributed to the dependence of transmissivity on the groundwater mound height at
Fig. 8 Simulations results of Scenarios A1, 2 and 3 for the Basalt aquifer
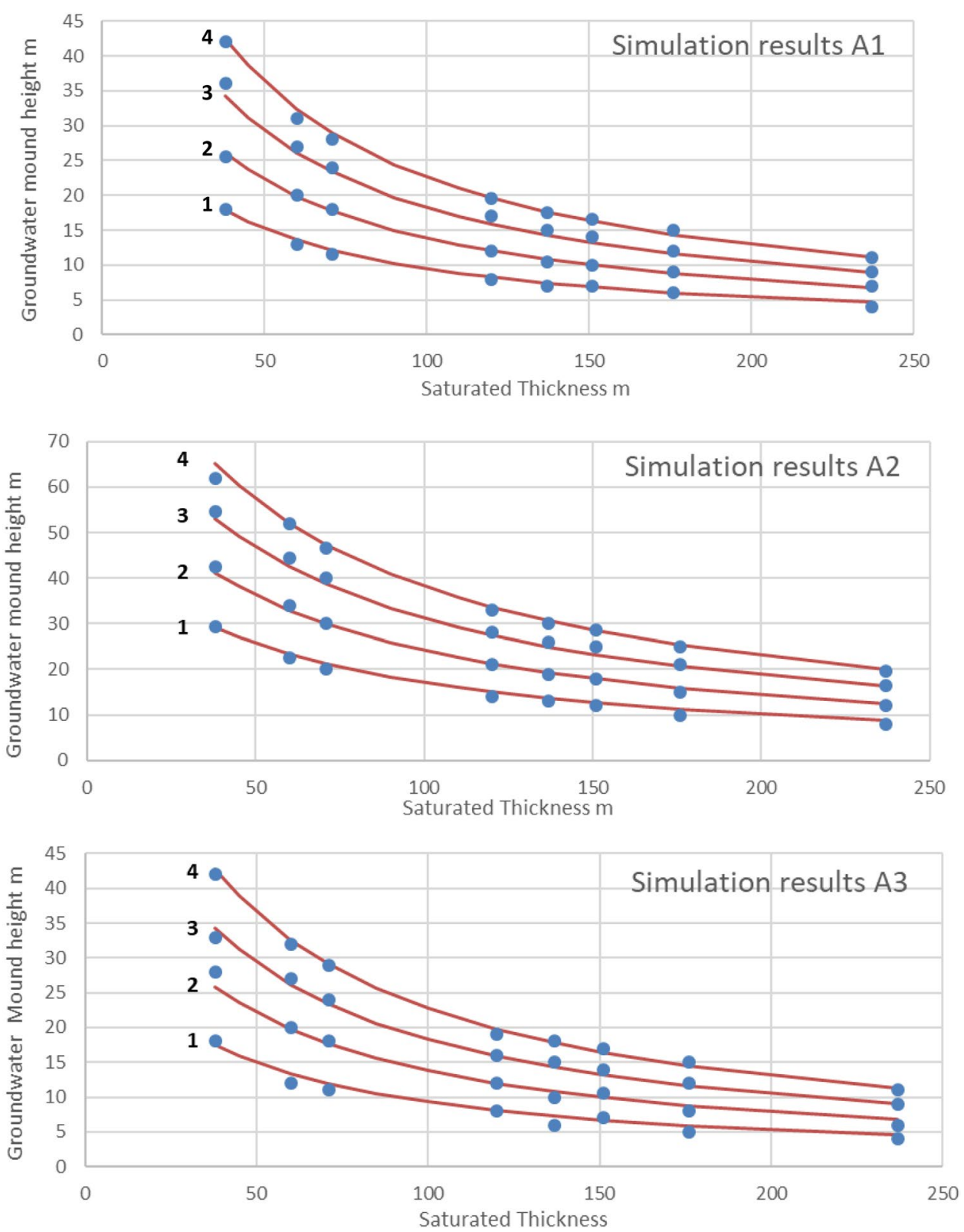
the infiltration location. A higher groundwater mound will increase transmissivity due to the higher local groundwater thickness. For low groundwater mounds and large aquifer saturated thicknesses this dependence can be ignored. However, the results show that for lower saturated thickness $(<60 \mathrm{~m})$ the errors associated with this dependence are large which sets a limit on the application of this approach for lower saturated thicknesses.

The error range and RMSD values of the equations used for the different aquifers in the model area are displayed in Table 4.

A plot of "observed" (heads computed by the numerical groundwater model) and resulting groundwater mound height based on the calibrated equation for the basalt and B4/5 are shown in Figs. 9 and 10.

Equation (3) can be applied to an aquifer with vertical $K$ ranging between $1.5 \mathrm{~m} /$ day and $0.75 \mathrm{~m} /$ day and a specific yield of 0.001 corresponding to the hydraulic characteristics

Table 4 Error range of based on the comparison between heads from the empirical equations and numerical model for the different aquifers in the model area

\begin{tabular}{lccc}
\hline Aquifer & RMSD $[\mathrm{m}]$ & Error range \\
\cline { 3 - 4 } & & Lower-bound & Higher bound \\
\hline Basalt aquifer & 1.12 & -2 & 3 \\
B4/5 aquifer $(T<60)$ & 4.43 & -19 & 18 \\
B4/5 aquifer $(T>60)$ & 76.79 & -9 & 9 \\
\hline
\end{tabular}

of the basalt aquifer for which the simulations were conducted. Equation (4) applies for values of vertical $K$ ranging between 0.12 and $0.06 \mathrm{~m} /$ day and a specific yield of 0.01 corresponding to the characteristics of the B4/5 aquifer for which the simulations were conducted. Equation 2 calculating height of groundwater mound underneath an infiltration basin can be further calibrated for aquifers with variable hydraulic characteristics (Sy and vertical $K$ ) and variable MAR structures. Based on Eq. 2 tables can be generated and regression coefficients $(\alpha, \beta$ and $\delta$ ) determined for a certain type of aquifer and specific MAR-structure and directly applied into GIS to create suitability maps.

\section{Sensitivity and uncertainty analysis}

The sensitivity of groundwater mound height with respect to a variation in aquifer transmissivity indicates the importance of including this hydraulic characteristic in MAR studies and the necessity of measuring aquifer transmissivity with high accuracy.

Sensitivities of the results for the different values of saturated thickness, and for the four water scenarios are calculated (Fig. 11). The calculation shows that the sensitivity of the horizontal hydraulic conductivity was higher for lower volumes of infiltrated water and higher values of saturated aquifer thickness.

Additionally, the derivative of Eq. 2 was determined to discuss how changes in transmissivity and infiltration
Fig. 9 Observation (numerical model result) vs. resulting GWM height from calibrated equation for the Basalt aquifer

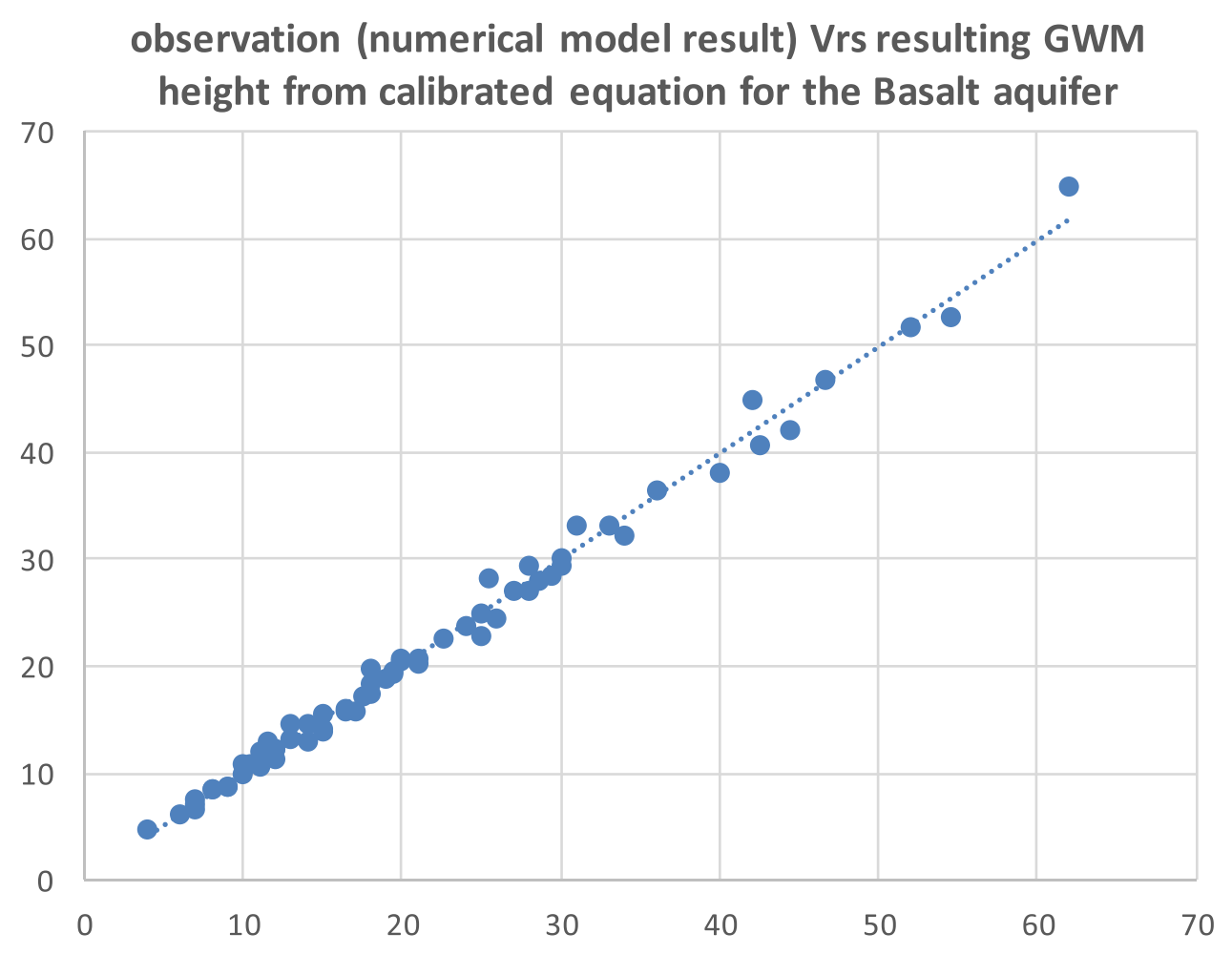


Fig. 10 Observation (numerical model result) vs. resulting GWM height from calibrated equation for the B45 aquifer

Fig. 11 Sensitivity of the results for the different values of saturated thickness, and for the four water scenarios

\section{observation (numerical model result) Vrs resulting GWM height from calibrated equation for the the B45 aquifer}

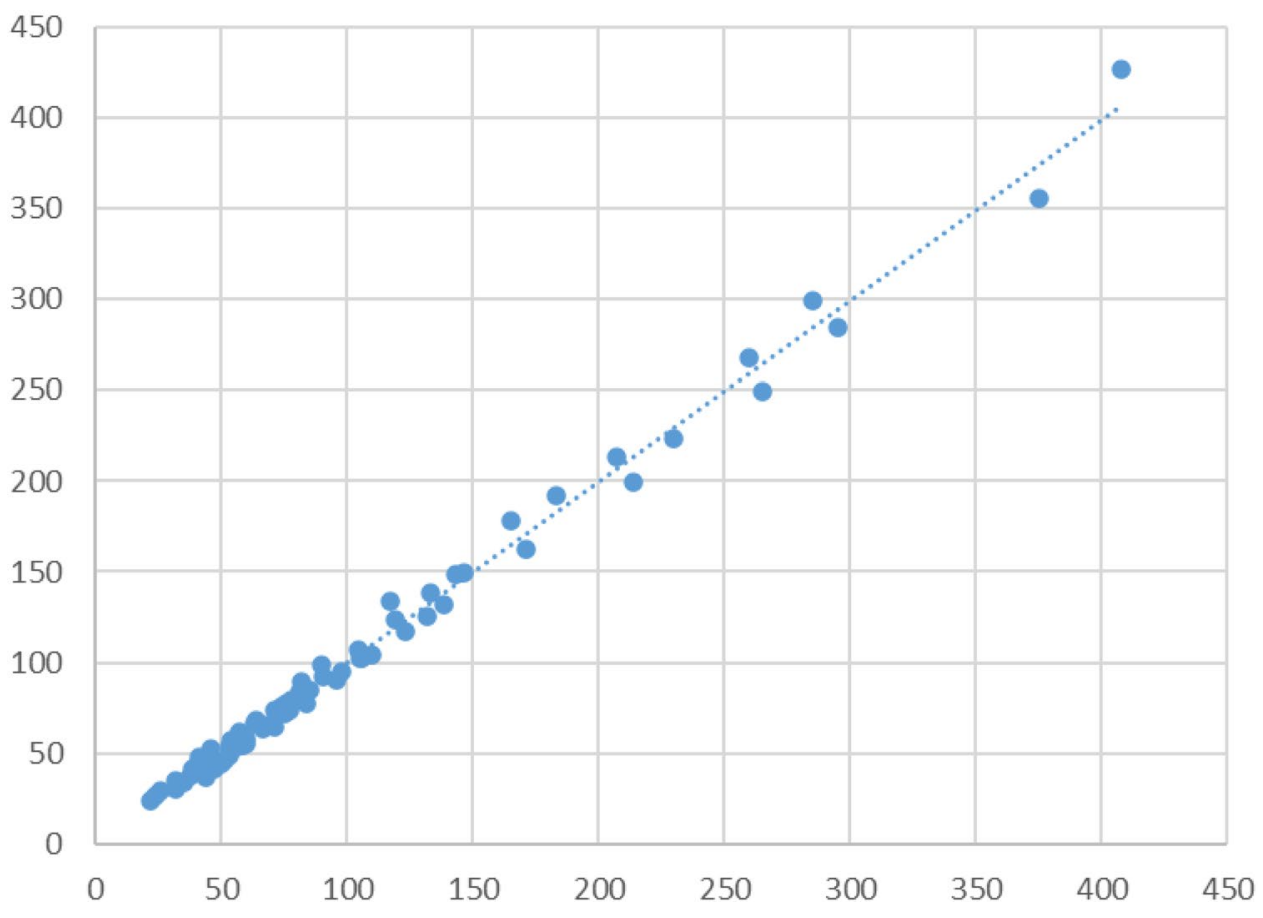

Sensitivity of results to $50 \%$ reduction in hydraulic conductivity

Water scenario 1 Water scenario $2 \quad$ Water scenario $3 \quad$ Water scenario 4

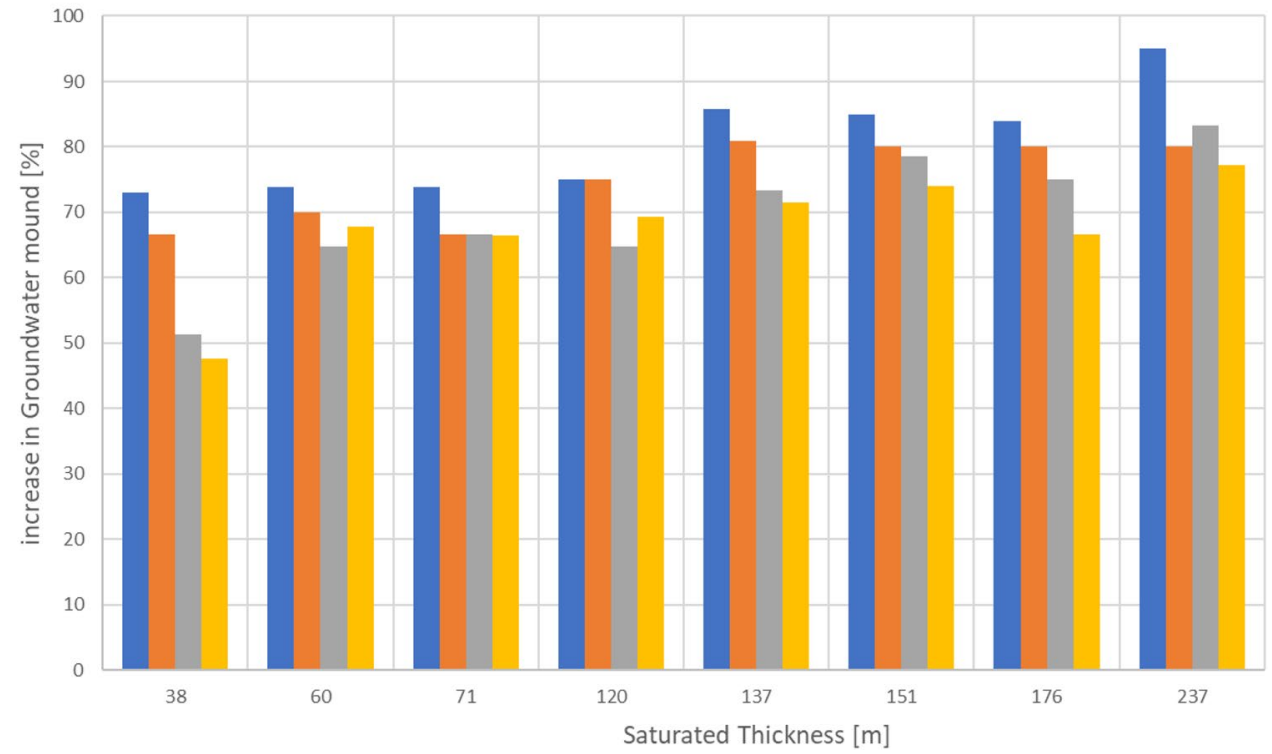


volume will impact the computed groundwater mound (Eqs. 5 and 6).

For a constant value of infiltration volume, height of groundwater mound is a reciprocal function of transmissivity, and for a constant transmissivity height of groundwater mound is a linear function of infiltration volume.

$\frac{\partial \text { (height of GWM) }}{\partial w}=\frac{1}{\beta T+\beta \delta}$

$\frac{\partial(\text { height of GWM })}{\partial T}=\frac{\alpha+W}{\beta(\delta+1)^{2}}$.

The new developed method is subject to a number of factors that reduce its certainty. These are

1. Erroneous estimation of infiltration rates will change the time required for infiltration. A lower infiltration rate will lead to longer times of infiltration, which would result in a lower groundwater mound, and vice versa.

2. A deviation from the assumed ratio between horizontal and vertical hydraulic conductivity (10:1) can affect the results, because lower or higher vertical hydraulic conductivity affects groundwater flow rates diverging from the recharge mound and thus the height of recharge mound. As a result of the complexity associated with measuring this ratio, and the possible spatial variation, the ratio (10:1) can serve as an initial reasonable guess.

3. Clogging problems can be faced as a result of sediment transport into the structure, which decreases the vertical permeability and thus infiltration rates considerably.

4. A deviation of the structural design of MAR ponds from the assumed designed (the dimensions and capacity of the infiltration basin) will lead to different results.

5. The impacts of vadose flow in the unsaturated zone on the formation of recharge mounds were neglected in this study.

6. The results of this study form a basis for a "base scenario" with options to conduct climate change scenarios. The results of the study are based on runoff events from the last 30 years. The findings can be further improved by including possible changes in storm events as a result of climate change.

\section{Conclusion}

In this study, numerical simulations of groundwater mounds beneath MAR-structures were used to calibrate a simple empirical equation that calculates the height of groundwater mounds as a function of aquifer transmissivity and the volume of infiltrated water. The sensitivity of the results was analyzed by conducting the simulations for different scenarios of hydraulic conductivity and infiltrated water volume. The high sensitivity of the results highlighted the importance of including these factors in MAR-suitability studies.

The empirical equations for the determination of the height of the recharge mounds for the basalt and B4/5 aquifer can be generalized, i.e. applied elsewhere for aquifers with similar hydraulic aquifer characteristics. Moreover, using the same approach, a set of equations could be further developed to cover a wide range of aquifer characteristics. This will reduce the effort of applying numerical simulations at each MAR-study, and yet offer a quantitative approach that considers the combined effect of hydraulic and geometric aquifer characteristics and volume of infiltrated water. The method offers an easy-to-use approach of excluding unsuitable areas for MAR. Further classification of suitable sites is necessary. Subdivisions into suitability classes can be accomplished based on available data (e.g. depth to groundwater).

The generated MAR suitability maps are considered as a first step for the delineation of suitable sites for MAR. Still, it is recommended to conduct a site-specific analysis (infiltration and pumping test, detection of impervious layers in the vadose zone) to derive all required parameter in more detail.

Funding Open Access funding enabled and organized by Projekt DEAL.

Open Access This article is licensed under a Creative Commons Attribution 4.0 International License, which permits use, sharing, adaptation, distribution and reproduction in any medium or format, as long as you give appropriate credit to the original author(s) and the source, provide a link to the Creative Commons licence, and indicate if changes were made. The images or other third party material in this article are included in the article's Creative Commons licence, unless indicated otherwise in a credit line to the material. If material is not included in the article's Creative Commons licence and your intended use is not permitted by statutory regulation or exceeds the permitted use, you will need to obtain permission directly from the copyright holder. To view a copy of this licence, visit http://creativecommons.org/licenses/by/4.0/.

\section{References}

Abadie J, Carpentier J (1969) Chapter 4: Generalization of the Wolfe reduced gradient method to the case of nonlinear constraints. In: Fletcher R (ed) Optimization. Academic Press, New York

Abu-Taleb MF (1999) The use of infiltration field tests for groundwater artificial recharge. Environ Geol 37(1):64-71

Al-Kharabsheh A (1995) Possibilities of artificial groundwater recharge in the Azraq Basin: potential surface water utilization of five representative catchment areas (Jordan). PhD Dissertation, Selbstverlag des Lehr- u. Forschungsbereichs Hydrologie und Umwelt am Inst. für Geologie 
Alkhatib J, Engelhardt I, Ribbe L, Sauter M (2019) An integrated approach for choosing suitable pumping strategies for a semiarid region in Jordan using a groundwater model coupled with analytical hierarchy techniques. Hydrogeol J s10040-019-01925-0

Alraggad M, Jasem H (2010) Managed aquifer recharge (MAR) through surface infiltration in the Azraq Basin/Jordan. J Water Resour Prot 2:1057-1070

Arabtech Consulting Engineering (1994) Groundwater investigation in the Azraq basin. Unpublished report, Ministry of Water and Irrigation, Water Authority, Jordan

Bhuiyan C (2015) An approach towards site selection for water banking in unconfined aquifers through artificial recharge. J Hydrol 523:465-474

Bouwer H (2002) Artificial recharge of groundwater: hydrogeology and engineering. Hydrogeol J 10:121-142

El-Naqa A, Al-Momani M, Kilani S, Hammouri N (2007) Groundwater deterioration of shallow groundwater aquifers due to overexploitation in northeast Jordan. Clean: Soil, Air, Water 35(2):156-166

Ghayoumian J, Ghermezcheshme B, Feiznia S, Noroozi AA (2005) Integrating GIS and DSS for identification of suitable areas for artificial recharge, case study Meimeh Basin. Isfahan, Iran, Environ Geol 47:493-500

Ghayoumian J, Saravi MM, Feiznia S, Nouri BA, Malekian A (2007) Application of GIS techniques to determine areas most suitable for artificial groundwater recharge in a coastal aquifer in southern Iran. J Asian Earth Sci 30:364-374

Glover RE (1961) Mathematical derivations as pertains to groundwater recharge. Agriculture Research Services USDA, Fort Collins

Goode J, Senior LA, Subah A, Jaber A (2013) Groundwater level trends and forecasts, and salinity trends in the Azraq, dead sea, Hammad, Groundwater basins, Jordan. Open-File Report, US Department of the Interior. US Geological Survey

Hantush MS (1967) Growth and decay of groundwater-mounds in response to uniform percolation. Water Resour Res 3(1):227-234

Heisig PM, Prince KR (1993) Characteristics of a groundwater plume derived from artificial recharge with reclaimed wastewater at East Meadow, Long Island, New York. Water Resources Investigations Report 91-4118. US Geological Survey

Hobler M, Margane A, Almomani M, Subah A (2001) Groundwater resources of northern Jordan volume-4 contribution to the hydrogeology of Northern Jordan. BGR-WAJ technical cooperation project
Lee T-C, Williams AE, Wang C (1992) An artificial recharge experiment in San Jacinto basin, Riverside, southern California. J Hydrol 140(1-4):235-259

Mahmoud SH, Alazba AA, Amin MT (2014) Identification of potential sites for groundwater recharge using a GIS-based decision support system in Jazan Region-Saudi Arabia. Water Resour Manage 28:3319-3340

McDonald MG, Harbaugh AW (1988) MODFLOW. A modular threedimensional finite difference ground-water flow model. US Geological Survey. Open-file report 83-875

MWI and GTZ (2003) NWMP, surface water resources. Jordan. The Hashemite Kingdom of Jordan

Rahman MA, Rusteberg B, Gogu RC, Ferreira L, Sauter M (2012) A new spatial multi-criteria decision support tool for site selection for implementation of managed aquifer recharge. J Environ Manag 99:61-75

Rahman MA, Rusteberg B, Uddin MS, Lutz A, Abu Saada M, Sauter M (2013) An integrated study of spatial multicriteria analysis and mathematical modelling for managed aquifer recharge site suitability mapping and site ranking at Northern Gaza coastal aquifer. J Environ Manag 124(2013):25-39

SCS National Engineering Handbook (1985) Section 4; hydrology. Soil conservation service USDA Washington, DC

Smith AJ, Pollock DW (2012) Assessment of managed aquifer recharge. Potential using ensembles of local models. Ground Water 50(1):133-143

Steinel A (2012) Pre-feasibility study for infiltration of floodwater in the Amman-Zarqa and Azraq basins, Jordan. Technical Cooperation Project No. 2002.3510.1 GeoSFF Study, Hannover 2012

Taheri A, Zare M (2011) Groundwater artificial recharge assessment in Kangavar Basin, a semi-arid region in the western part of Iran. Afr J Agric Res 6(17):4370-4384

Zaidi FK, Nazzal Y, Ahmed I, Naeem M, Jafri MK (2015) Identification of potential artificial groundwater recharge zones in Northwestern Saudi Arabia using GIS and Boolean logic. J Afr Earth Sc 111:156-169

Publisher's Note Springer Nature remains neutral with regard to jurisdictional claims in published maps and institutional affiliations. 